Clinica Chimica Acta, 96 (1979) 91-96

(C) Elsevier/North-Holland Biomedical Press

CCA 1069

\title{
A SENSITIVE FLUORESCENT ASSAY FOR $N$-ACETYLTRANSFERASE ACTIVITY IN HUMAN LYMPHOCYTES FROM NEWBORNS AND ADULTS
}

\author{
MIRIAM H. MEISLER * and CYNTHIA REINKE \\ Department of Human Genetics, University of Michigan, 1137 E. Catherine Street, \\ Ann Arbor, MI 48109 (U.S.A.)
}

(Received February 2nd, 1979)

\section{Summary}

We have developed a simplified assay for the enzyme $\mathrm{N}$-acetyltransferase, based upon the loss of fluorescence after acetylation of the substrate $p$-aminobenzoic acid. This method is sufficiently sensitive to permit the quantitation of $N$-acetyltransferase activity in $10^{5}$ human lymphocytes. Using this method, we have compared the level of $N$-acetyltransferase activity in lymphocytes from adult peripheral blood and from cord blood samples.

\section{Introduction}

The enzyme $N$-acetyltransferase (EC 2.3.1.5) modifies aromatic amines by acetylation of the amino group. A genetic polymorphism determining liver $\mathrm{N}$-acetyltransferase activity levels in human populations is responsible for individual variation in sensitivity to therapeutic doses of isoniazid and other drugs [1]. This enzyme is also present in rabbit leukocytes [2] and human lymphocytes [3]. We have developed a convenient assay procedure which is sufficiently simple and sensitive for screening purposes. Individual variation in levels of $N$-acetyltransferase activity is of particular interest because of its role in metabolism of environmental mutagens and carcinogens [4]. This simple quantitative assay may be useful for the identification of population subgroups with genetic differences in the rate of metabolism of exogenous aryl amines.

\section{Methods}

Unless indicated, chemicals were purchased from Sigma. $N$-Acetyl-p-aminobenzoic acid was obtained from Aldrich.

* To whom correspondence should be addressed. 
Preparation of lymphocytes. Ten $\mathrm{ml}$ samples of whole blood from adults or cord blood from their newborn offspring were collected at the time of birth with the informed consent of the participants. These samples were stored for 1 day at $4^{\circ} \mathrm{C}$ in the presence of acid citrate dextrose (B and D Vacutainers). After centrifugation for $7 \mathrm{~min}$ at $1000 \times \mathrm{g}$, the buffy coat (volume $1 \mathrm{ml}$ ) was diluted with $3 \mathrm{ml}$ of phosphate buffer [5] and layered over $3 \mathrm{ml}$ of FicollHypaque (Pharmacia). After centrifugation for $30 \mathrm{~min}$ at $400 \times \mathrm{g}$, lymphocytes were recovered at the interface. The lymphocytes (ca. $10^{7}$ cells) were homogenized in $1 \mathrm{ml}$ of the phosphate buffer at $4^{\circ} \mathrm{C}$ with a Bronson Sonifier using pulsed sonication (50 sec, $20 \%$ sound).

Enzyme assay. Reaction conditions were identical to those described by Hearse and Weber [2]. Assay mixtures contain $4 \times 10^{-5} \mathrm{~mol} / \mathrm{l} p$-aminobenzoic acid (pABA) and $2 \times 10^{-3} \mathrm{~mol} / \mathrm{l}$ acetyl $\mathrm{CoA}$ in a total volume of $40-120 \mu \mathrm{l}$ of phosphate buffer, pH 7.4. The reaction is stopped by the addition of $1 / 4$ volume of $25 \%$ trichloroacetic acid. After centrifugation at $800 \times \mathrm{g}$ for $5 \mathrm{~min}$, an aliquot of the supernate is diluted with $2 \mathrm{ml}$ of $0.5 \mathrm{M}$ sodium carbonate. The fluorescence of residual substrate was measured with an Aminco Spectrofluorimeter using an excitation wavelength of $270 \mathrm{~nm}$ and an emission wavelength of $340 \mathrm{~nm}$. For purposes of comparison, the spectrophotometric assay was carried out as described by Hearse and Weber [2]. Enzyme activity is expressed as nmoles of substrate metabolized per h per mg protein.

Protein was determined by the method of Lowry et al. [6] using bovine serum albumin as standard.

\section{Results}

Effect of acetylation on the fluorescence of p-aminobenzoic acid

$p$-Aminobenzoic acid, which has been commonly employed as a substrate for the enzyme $N$-acetyltransferase, is a highly fluorescent compound [7]. Since acetylation of aromatic amines is frequently accompanied by loss of fluorescence [8], we compared the fluorescence spectra of pABA and $N$-acetyl-pABA. The fluorescence observed for the $N$-acetyl-pABA was approximately $1 \%$ of the value for an equimolar solution of pABA (Fig. 1). To determine whether this low residual fluorescence was the result of contamination of the $N$-acetylpABA sample with free pABA, we measured primary amino groups in the $N$-acetyl-pABA by diazotization [9]. The results indicated that our sample of $N$-acetyl-pABA contains approximately $1 \%$ pABA. The residual fluorescence of $N$-acetyl-pABA is probably due to this contamination.

Since acetylation of pABA results in virtually complete loss of fluorescence, measurement of fluorescence can be used to quantitate the extent of conversion of pABA to the acetylated compound.

\section{Assay requirements}

The assay is based on measurement of substrate depletion. Enzyme and substrate concentrations are chosen to produce conversion of $20-30 \%$ of the initial substrate to product. The fluorescence of the complete reaction mixture is due predominantly to pABA (Table I). Since there is some quenching of fluorescence by acetyl-CoA, it is included in control mixtures. 


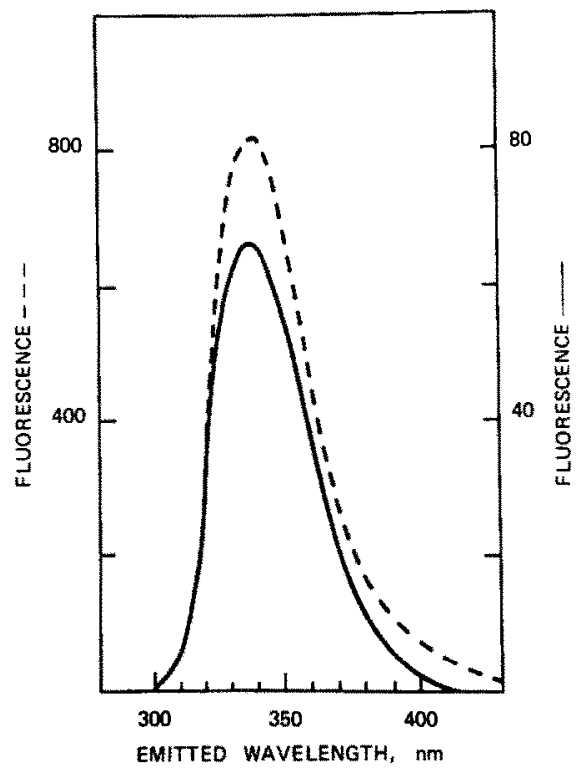

Fig. 1. Fluorescence emission spectrum of acetylated and non-acetylated $p$-aminobenzoic acid. Excitation wavelength was $270 \mathrm{~nm} . \ldots . .10^{-5} \mathrm{~mol} / \mathrm{h}$-aminobenzoic acid: $-10^{-4}$ mol $/ \mathrm{h}$-acetyl-p. aminobenzoic acid.

When acetyl-CoA is omitted from the reaction mixture there is no change in fluorescence. This dependence on acetyl-CoA indicates that acetylation is the only reaction catalyzed by these lymphocyte extracts which results in conversion of pABA to a nonfluorescent product. Enzyme activity is calculated by subtracting the fluorescence of the complete reaction mixture from the fluorescence of an identical mixture which was not incubated at $37^{\circ} \mathrm{C}$. In Table I, the specific activity was equivalent to $75 \mathrm{~nm} / \mathrm{h} / \mathrm{mg}$ protein. Under these conditions, the rate of the reaction is linear for $20 \mathrm{~min}$ (Fig. 2) and is proportional to enzyme concentration.

\section{$N$-Acetyltransferase activity of human lymphocytes}

The major portion of $N$-acetyltransferase in human blood is associated with the lymphocytes [10]. We measured the activity of $N$-acetyltransferase in human lymphocytes with the new fluorescent method, and compared the results with

\section{TABLE I}

\section{FLUORESCENT ASSAY OF N-ACETYLTRANSFERASE}

Reactions conditions are described in Methods. The reaction mixture contained $10^{5}$ lymphocytes.

\begin{tabular}{ll}
\hline Reaction components & Fluorescence units \\
\hline Controls: & \\
Minus enzyme & 69 \\
Minus incubation & 69 \\
Minus actyl-CoA & 72 \\
Minus $p$-aminowenzoic acid & 4 \\
Complete mixture & 49 \\
\hline
\end{tabular}




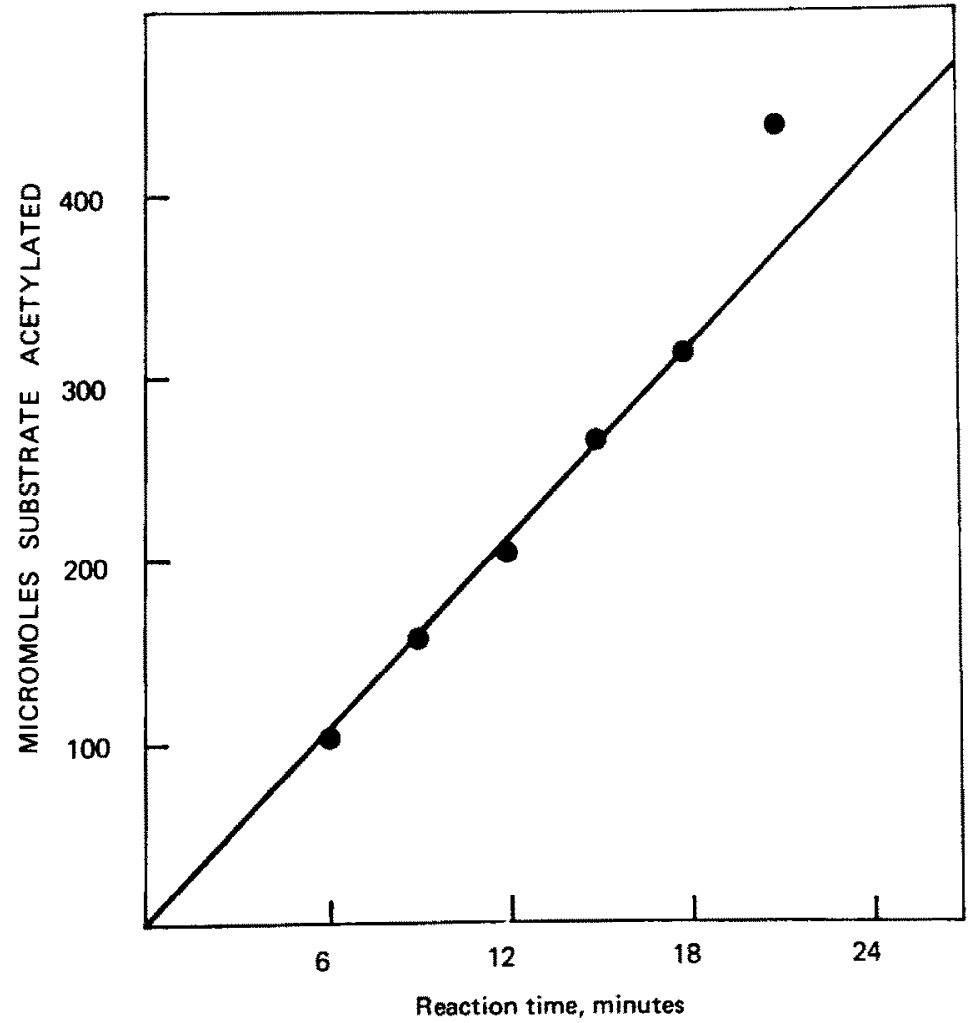

Fig. 2. Time course of the $N$-acetyltransferase assay. Reaction was followed by measurement of the loss of substrate fluorescence.

those obtained by the spectrophotometric procedure. Lymphocytes were prepared from pooled samples of adult or cord blood. The enzyme activity in lymphocytes from cord blood was approximately half of that in adult blood (Table II). Since the individuals in the newborn group sample are offspring of

\section{TABLE II}

$N$-ACETYLTRANSFERASE ACTIVITY OF HUMAN LYMPHOCYTES FROM ADULT AND CORD BLOOD

Ten $\mathrm{ml}$ blood samples from four adults (two males and two females) or from two newborns were pooled prior to preparation of lymphocytes.

\begin{tabular}{lll} 
Sample & \multicolumn{2}{l}{$N$-Acetyltransferase $(\mathrm{nm} / \mathrm{h} / \mathrm{mg}$ protein) } \\
\cline { 2 - 3 } & Absorbance assay & Fluorescence assay \\
\hline Adult Iymphocytes & & \\
$\quad$ I & 148 & 136 \\
II & 136 & 128 \\
III & 139 & 153 \\
Cord blood lymphocytes & & \\
I & 71 & 73 \\
II & 74 & 67 \\
III & 75 & 60 \\
\hline
\end{tabular}


the adult sample, the quantitative difference between the two groups is unlikely to result from genetic differences.

Our results are in good agreement with the average value of $155 \mathrm{~nm} / \mathrm{h} / \mathrm{mg}$ protein previously reported for adult lymphocytes [10]. The agreement between the values we obtained by the fluorimetric and spectrophotometric assays indicates that the same enzyme is detected by the two.

\section{Discussion}

The fluorimetric assay of $\mathrm{N}$-acetyltransferase has several advantages over the spectrophotometric method: it is faster, more convenient, and, in our hand, more reproducible than the earlier method. In addition, its five-fold greater sensitivity makes it possible to measure the enzyme in smaller blood samples. We have routinely assayed $N$-acetyltransferase in lymphocytes prepared from $10 \mathrm{ml}$ blood samples; we have also been able to utilize 1-ml samples.

While both assays measure depletion of the substrate $p$-aminobenzoic acid, they differ in mechanism. The spectrophotometric assay detects the loss of free amino groups; the fluorometric assay detects modifications which reduce substrate fluorescence. Therefore, it is critical to establish both dependence on acetyl-CoA, and quantitative agreement with the spectrophotometric assay, when applying the fluorescent method to a new tissue.

Storage of whole blood for more than $24 \mathrm{~h}$ prior to isolation of lymphocytes caused a reduction in $N$-acetyltransferase activity. Repeated freezing of cell extracts also inactivated the enzyme. However, the enzyme may be stabilized by the addition of $10^{-6} \mathrm{~mol} / \mathrm{l}$ acetyl-CoA prior to freezing (Brenner, W., McQueen, C. and Weber, W.W., unpublished results).

Individual mammalian enzymes are characterized by unique temporal patterns of expression during ontogenic development. For example, many of the microsomal drug metabolizing enzymes of liver are absent or very low in newborn animals, and reach adult levels at different rates during postnatal development [11]. In contrast to these enzymes, we find that $\mathrm{N}$-acetyl transferase is present in cord blood lymphocytes at approximately 50\% of the adult level. Drug acetylation during the perinatal period has also been observed by others [12]. In one study, in vivo acetylation of $p$-aminobenzoic acid was detected in 2-day-old infants [13]. $N$-Acetyltransferase thus differs from some other drug metabolizjng enzymes in its relatively early time of appearance. The metabolic role of this enzyme during the perinatal period is not yet known.

\section{Acknowledgement}

This research was supported by DOE-Contract 2828. We are grateful to Drs. C. McQueen and W. Weber for advice.

\section{References}

1 Harris, H. (1975) The Principles of Human Biochemical Genetics, pp. 251-254, North-Holland, Amsterdam

2 Hearse, D.J. and Weber. W.W. (1973) Biochem. J. 132. $519-526$

3 McQueen, C.A. and Weber, W.W. (1977) Am. J. Hum. Genet. 29, 73a 
4 Glowinski, I.B., Radtke, H.E. and Weber, W.W. (1978) Mol. Pharmacol, 14, $940-949$

5 Medzihradsky, F. and Metcalf, J.I. (1975) J. Lab. Clin. Med. 85, 342-350

6 Lowry, O.H., Rosebrough, N.J., Farr, A.L. and Randall, R.J. (1951) J. Biol. Chem. 193, 265-275

7 Duggan, D.E., Udenfriend, S.L., Bowman, R. and Brodie, B.B. (1957) Arch. Biochem. Biophys. 68, $1-14$

8 Udenfriend, S.L. (1962) Fluorescence Assay in Biology and Medicine, p, 31, Academic Press, New York

9 Weber, W. (1971) Methods in Enzymology (Tabor, H. and Tabor, C., eds,), Vol. 17, Part B, pp. 805 811

10 McQueen, C. (1978) Ph.D. Thesis, University of Michigan

11 Testa, B. and Jenner, P. (1978) Drug Metabolism Chemical and Biochemical Aspects, pp. 397-401. M. Dekker, New York

12 Dutton, G.J. (1978) Ann. Rev. Pharm. Toxicol. 18, 17-35

13 Vest, M.F, and Salzberg, R. (1965) Arch. Dis, Child. 40, 97-105 